\title{
ALFEREZ Y MAYORDOMO REAL EN EL SIGLO XIII
}

\author{
Por \\ FRANCISCO VEAS ARTESEROS \\ MARIA DEL CARMEN VEAS ARTESEROS
}


The article examines two institutions as they existed in the 13th Century, to be precise, during the reigns of Ferdinand III and Alfonso $\mathrm{X}$ : the royal Mayordomo and Alferez. The study concentrates, less on the posts themselves as intitutions, than on the figures who occupied them in the period in which these monarchs ruled over Castille. Their importance in Castillian political life is undeniable, since their proximity to the king himself, as well as the extent of their territories, only enhance their power and influence inside and outside the Cour. Both the Mayordomo, whose role was administrative, in charge of the fimances, and the Alfé$r e z$, whose duties were military and judicial, were nonetheless to trascend the actual limits of their posts. 
La estructura de la corte regia y de la administración central del Estado castellano adquirió una mayor complejidad en la Baja Edad Media, periodo en el que el avance de la Reconquista impuso una reorganización y un aumento del número de los oficiales palatinos. Es ahora cuando se organiza la cancillería regia como organismo central de la administración y las altas dignidades de la corte, atribuidas a grandes señores, se hicieron más honorificas que efectivas, al mismo tiempo que los oficios públicos comienzan a ser encomendados a juristas o letrados. Pero, no obstante, en muchos aspectos persistió la confusión entre los oficiales públicos de la administración central y los del servicio de la corte, por lo que a partir del Siglo XIII se trataron de delimitar las funciones de los oficiales de la administración palạtina, que en Castilla quedaron reguladas por las Partidas. Nosotros vamos a ocuparnos ahora de dos importantes oficios palatinos como lo son el Mayordomo y el Alférez del rey, así como las personas que ostentaron tales cargos durante los mandatos de Fernando III y su sucesor Alfonso X.

\section{MAYORDOMOS REALES EN EL SIGLO XIII}

Al frente de la hacienda real castellana se encuentra el Mayordomo Mayor, al que debían rendir cuentas de todos los ingresos y gastos los otros oficiales de la hacienda regia, tal y como el propio rey Sabio señala: «-ca al mayordomo pertenesçe tomar cuenta de todos los ofiçiales, tanbien de los que fazen las despensas de la corte como de los otros que 
reçiben las rentas e los otros derechos de qualquier manera que sean, asi de mar como de tierra. E el deue, otrosi, saber todo el auer que el rey manda dar como lo dan e en que manera...) (1), y para desempeñar este cometido debía ser hombre «... de buen linaje e acuçioso e sabidor e leal...), características que en mayor o menor grado van a concurrir en todos aquellos que ostentan el cargo de Mayordomo Mayor de la corte en los reinados de Fernando 111 y Álfonso $\mathrm{X}$.

GONZALO RODRIGUEZ GIRON (1198-1216 y 1217-1231)

Hijo de don Rodrigo Gutiérrez y doña María de Guzmán, fuc cabeza destacada de una de las familias nobiliarias que más influencia ejercerían en la vida política castellana del Siglo XIIl, llegando a tener una gran preponderancia en la élite política del reino como hombre de confianza de Alfonso VIII.

Ocupó la mayordomía real desde el 11 de Abril de 1198 hasta la muerte de Alfonso VIII y, posteriormente, hasta el 29 de Diciembre de 1216, año en que fue cesado y sustituido por Martín Muñoz (2), como consecuencia de la acción del conde don Alvaro Núnez de Lara a quien, en 1215, había sido traspasada, de manos de Garcí Lorenzo, la tutela del futuro monarca, Enrique I. En efecto, el conde, tras prestar juramento de fidelidad ante la reina doña Berenguela, partió de Burgos con el rey niño en contra del parecer de la lglesia y de los nobles, provocando el alejamiento del bando que capitaneaba Gonzalo Rodríguez quien a partir de ese momento se uniria al nuevo partido nobiliario surgido alrededor de la reina, a la cabeza del cual se encontraba don Lope Díaz de Haro. Pronto don Alvaro se percató de la influencia y poder que podía alcanzar Rodríguez Girón y para tratar de evitarlo se propuso combatirlo militarmente, por lo que al frente del ejército real asaltó el valle de Trigueros y arrasó las posesiones de Girón hasta llegar a Carrión (3).

(1) Partidas, II, IX, XVII.

(2) Gonzílez, J: Rejnado y Diplomas de Fermando III. Estudio. Córdoba, 1980, p. 156. p. 157.

(3) Ballesteros, A: Affonso $X$, Barcelona, 1963; págs. 21-2\%. Goniźlez, J: Op. cit., 
Sin embargo un acontecimiento acaecido al poco tiempo traería consigo un profundo cambio en la situación. La infortunada muerte del heredero al trono provocó la calda del partido dirigido por Núñez de Lara, lo que fue aprovechado por don Gonzalo para situarse al frente de los nobles descontentos con el gobierno del conde de Lara, que ahora cerraban filas en torno a la reina. Junto a Lope Díaz de Haro, velará por los derechos al trono del infante don Fernando a quien, en Julio de 1217, la reina cederá en Valladolid las prerrogativas de la Corona de Castilla. En Septiembre de ese mismo año Gonzalo Rodríguez aparece nuevamente al frente de la mayordomía real, cargo que ocupará hasta Octubre de 1231 (4), fecha en que aparece por última vez confirmando los privilegios rodados (5).

Recuperado nuevamente el cargo, Rodríguez Girón continuó las hostilidades contra Núñez de Lara, ejemplo de lo cual es el enfrentamiento que tuvo lugar en Bilforado, donde el mayordomo real fue apresado. Doña Berenguela se aprestó a pactar su liberación, y su rápida acción propició el apresamiento del conde de Lara, que tuvo que pagar muy cara su libertad al verse forzado a entregar varios lugares al monarca y permanecer bajo la custodia de Gonzalo Rodríguez hasta que se cumpliese lo pactado. Pero los enfrentamientos no acabaron aqui y las luchas continuarían hasta la firma de una tregua en 1218, tras el cerco de Medina del Campo, en donde Rodríguez Girón, Diaz de Haro y otros fueron sitiados (6).

(4) Vid. Gonzílezz, J: Op. cit. II. Diplomas (1217-1232). Córdoba, 1983. Docs. 2, 4, 6-11, $13-18,20,22,28-30,32,34-36,39-47,49-53,57,58,63-65,67,68,70,72-75,77,78,80-82$, $84,85,87-90,93,95,98-100,102,103,108-113,115-119,121,132,134,136,138-148,150$, $153-158,160,161,163-166,168.170,172,173,175,177.179,181,184-188,193-195,198$, $199,201,203-211,213,215-218,222,223,225,229,231,238,240-244,247,249-251$, $254-257,260,265-269,272,275,278,280,281,284,287,289,295-298,306,308,311-313$, $316,318,321,322,336,338-343,345,350,352$ y 354 .

(5) Debió cesar en Octubre, por cuanto en el privilegio dado en Aguilar, 8-X-1231, todavía aparece su firma de confirmación, pero en otro posterior, dado en Valladolid el 27 del mismo mes no figura la reserva de espacio para la firma del Mayordomo, anunciándose la vacante en el cargo en el privilegio del 28 de Noviembre del mismo año. Vid. Gonzálezz, J: Op. cii. Il. Docs. 354, 358 y 370.

(6) Ballesteros, A: Op. cit. pp. 33-35. 
Una vez pacificado el reino y desaparecido el peligro representado por el conde de Lara, se consolida la posición y linaje de Gonzalo Rodríguez Girón, cuya participación junto al rey en jornadas importantes fue continua. En pago a sus buenos servicios, Fernando III le permitió gozar de numerosas tenencias entre las que figuran Monzón, Liébana y Pernia, y compartió con su hermano, Rodrigo Ruiz, la importante tenencia de Carrión, que constituia junto con sus otras propiedades de Tierra de Campos, la mayor parte de sus posesiones, amén de las rentas que percibía entre las que destaca por su importancia el portazgo de Valladolid.

Casado en dos ocasiones, de su primera mujer, doña Sancha Ruiz, tuvo siete hijos uno de los cuales, Rodrigo González, llegaría a sucederle en el cargo, tras el corto espacio de tiempo que ocupó la mayordomía García Fernández. A él se deba la construcción del monasterio cisterciense de Matallana, cerca de Meneses, y el hospital de Carrión, en donde reposan sus restos.

\section{GARCIA FERNANDEZ DE VILLAMAYOR (1232-1238)}

Muerto don Gonzalo Rodríguez Girón, se anuncia la vacante oficial de la mayordomía el 28 de Noviembre y continúa esta situación hasta el 6 de Febrero de 1232 (7).

El nombramiento de García Fernández como «Maiordomus Curie Regis», debió producirse a los pocos días de la expedición del documento antes citado, pues el 16 de Febrero de 1232 aparece ya ostentanto el cargo (8). Ya anteriormente habra ejercido el puesto de mayordomo de 394.

(7) Vid. Gonzál.ez, J: Op. cit. Il. Docs. 358-360, 367, 370, 372, 373, 383, 385, 386, 392 y

(8) Nos resulta bastante extraña la aparición de Gonzalo Rodríguez como Mayordomo Mayor confirmando los privilegios fechados el 31-VIII-1232 en Toro. GonzÁlez, J: Op. cit. Doc. 481 y 1234-X-18, Burgos, Burriel. A. M: Memorias para la vida del santo rey don Fermando III. Anotadas y editadas por Miguel de Manuel Rodríguez. Barcelona, 1974, I, p. 442, debiendo tratarse de errores del escribano en lo referente a la era. 
la reina doña Leonor, entre los años 1211 y 1213 , y al morir ésta pasó a serlo de doña Berenguela (9), hasta su posterior nombramiento como mayordomo real de Fernando III, cargo que ocupara hasta Julio de 1238 (10). Contaba don García con cuantiosos bienes en Castilla y su bien provado valor en jornadas difíciles y decisivas, cuando el rebelde poderío de los Lara sembraba la discordia en tierras castellanas, le valió, a elección personal de doña Berenguela, la tutela del infante don Alfonso, quien al cumplir un año fue trasladado a Villaldemiro en donde se intaló con su tutor y su esposa doña Mayor Arias.

Desde los tiempos de Alfonso VIII fue aumentando sus posesiones, adquiriendo propiedades cerca de Muñó y, como fruto de sus leales servicios, obtuvo de Fernando III unas casa en Toledo y heredades en Villahoz, Escuderos, Higueruela y sus términos (11), disfrutando, además, de algunas tenencias importantes, acrecentadas por las grandes posesiones que doña Berenguela le otorgó en la comarca de Haza, en 1231, las cuales, con acuerdo del rey y de la reina Berenguela, don García cedió a la Orden de Santiago, con excepción de las propiedades de Torregalindo, a cambio de cuanto dicha Orden posefa en Amusco, Melgarejo y Castrojeriz. Además hemos de señalar la acumulación de derechos sobre la Iglesia de Villamayor, la compra realizada en 1227 a la Orden de Santiago de una heredad en Aranzo de la Torre y otros pueblos, los privilegios reales ganados a favor del monasterio cisterciense de Villamayor, por él fundado, con amparo y libertad de pastos en los montes de Lerma, $y$, por último, la concesión del señorio de Manzaneda, en territorio de Limia, hacia 1232, una vez que don García dejó la tutela de don Alfonso (12). No es de extrañar que su patrimonio se viera tan favorecido

(9) Stranano, L.: El Mayordomo Major de doria Berenguela. Madrid, 1934, hace un interesante estudio sobre García lernández y su familia.

(10) Burriel, A. M: Op. cit. I, pp. 411, 421, 425, 430 y 442. Gonzíl.ez, J: Op. cit. I, pp. $151-152, y$ II, Docs. 396, 398, 399, 401-403, 408, 409, 411,413-415, 418, 419-426, 431, 432, $434-436,439,441,443,444,447,449.451,454,455,457,459,461,462,466,469,470$, $471-473,476,479,483,484,487,491$ y 494.

(11) Serrano, L: Op. cit. Apéndice Documental X.

(12) Serrano, L: Op. cit. Apéndice Documental XV. 
si tenemos en cuenta los importantes servicios que prestó, ya que, además de los mencionados, participó jusnto a Fernando III en el sitio de Jaén realizado en 1230 , y en el posterior viaje que el monarca castellano emprendió a León, así como en el asedio de Córdoba.

Una vez cesado en el cargo de Mayordomo, volvió a ocupar la mayordomía de la reina doña Berenguela, que se prolongaría hasta 1240.

RODRIGO GONZALEZ GIRON (1238-1246 y 1248-1252)

Hijo de Gonzalo Rodríguez Girón, accede al cargo en Agosto de 1238 (13), ocupándolo hasta Febrero de 1246 (14) en que es cesado, en opinión de Julio González, a causa de su primo Rodrigo Gómez de Cisneros. La vacante en la mayordomía se prolongará por espacio de algo más de un año, exactamente y siempre en opinión de Julio González, desde el 24 de Diciembre de 1246 hasta el 27 de Enero de 1248, si bien hay que hacer notar que aparece nuevamente ocupando la mayordomia siete días antes de esta última fecha (15), no tenemos noticias de lo que sucede en el cargo desde que se produce el cese hasta la declaración de vacante oficial del mismo. La segunda etapa abarcará hasta Abril de 1252, último año del reinado de Fernando III, período durante el cual prestó brillantes servicios a la monarquía (16).

Antes de ocupar la mayordomía mayor había colaborado con el monarca participando en el cerco de Córdoba, acompañando al infante don Alfonso en su venida al reino de Murcia en 1243, y de nuevo a Fernando III al reino de Granada; destacó en la conquista de Sevilla y fue en-

(13) El primer documento en que aparece está fechado en $31-V I I 1-1238$.

(14) Burriel, A. M: Op. cit. pp. 442, 447, 450 y 470. Torres Fontes,j: Colección de Docu. mentos para la Historia del Reino de Murcia (en adelante CODOM), IIl. Murcia, 1973; Docs. I, VIl y IX.

(15) 1248-1-20, Real sobre Sevilla. Vid. Burriel, A. M: Op. cit., p. 493.

(16) Buraiel, A. M: Op. cit., pp. 494, 508, 515, 527 y 536. Según González, J: Op. cit. I; p. 118, el último documento en el que aparece es del 25 de Abril de 1252. 
viado a Carmona para tomar posesión de la capital andaluza cuando se entregó al monarca castellano.

Al igual que su padre, se vio enriquecido por las mercedes y privilegios concedidos en pago a sus servicios. De esta manera, aparte de sus posesiones en Carrión, en 1243 el infante don Alfonso le confía la tenencia de Elche, pero entre las propiedades que obtuvo destacan sobre todo los donadios que en 1252 recibió en el repartimiento de Sevilla, donde se le otorgaba la aldea de Villalba con sus términos, posteriormente entregada a la Orden de Calatrava (17).

Fallecido Fernando III, su hijo Alfonso X no establece, en principio, importantes cambios en la estructura y componentes de su corte, por lo que la mayor parte de los que ocupaban cargos relevantes a la muerte de su antecesor continuaron en ellos. Pero no sucedió lo mismo con el puesto de Mayordomo Mayor, en el que don Alfonso decretó el cese de Rodrigo González Girón.

\section{JUAN GARCIA DE VILLAMAYOR (1253-1258)}

Sustituto de González Girón, era hijo del que fuera también Mayordomo real García Fernández y de doña Mayor Arias, que ya desde 1242 y hasta 1252 aparece confirmando los privilegios reales como prolongación de su padre. Con tales antecedentes resulta fácil imaginar el motivo que llevó a Alfonso $\mathrm{X}$ a designarlo para ocupar el cargo de Mayordomo, puesto que era hijo de sus queridos tutores y compañero de juegos de su niñez.

Desempeñó la mayordomía mayor de Alfonso el Sabio desde 1253 hasta $1258(18)$, año a partir del cual se anuncia que el cargo se encon-

(17) Ballesteros, A: Op. cit., p. 80; también GonzŔlez, J: Op. cit. pp. 159-160.

(18) Torres Fontes, J: CODOM, III. Docs. XV, XVII, XXI. XI.VI. 
traba vacante (19), al cesar Juan García en sus funciones. Ballesteros se pregunta si se produjo algún incidente que menguase, de modo pasajero, el afecto profesado por el rey a su más intimo colaborador, ya que más tarde, volvería a aparecer en otro cargo de confianza, pero lo cierto es que los documentos nos dan pruebas contundentes de que el 25 de Enero de 1259 la mayordomía se encontraba vacante y el 24 de Marzo de 1261 la ocupaba ya don Fernando de la Cerda (20). Nos inclinamos a pensar que lo único que sucedió fue que Juan García renunció a su cargo para ocupar el de almirante, para el que Alfonso X lo habla designado en Julio de 1260 (21), debiendo ser Mayordomo en funciones hasta su nombramiento efectivo como "Adelantado Mayor de la mar", para dirigir la flota y llevar a efecto la conquista de Cádiz (22).

Es indudable que este personaje prestó importantes servicios a la Corona y así lo demuestra su participación en la empresa reconquistadora, llegando a ocupar la tenencia de Alhama de Murcia. En el repartimiento de Sevilla recibió un importante donadio al que impondría el nombre de Villamayor, obteniendo posteriormente otro en Sanlúcar (23); y ya, en 1263, figura junto a su hermano, Alfonso García, deslindando los límites entre Castilla y Portugal, según lo acordado entre Alfonso X y su homónimo portugués (24).

\section{INFANTE DON FERNANDO (1261-1274)}

Tras un espacio aproximado de dos años en los que la mayordomía se encuentra vacante, viene a ocupar el relevante cargo un miembro de

(19) Torres Fontes, J: CODOM, III. Docs. LlI. También Brllesteros, A: Op. cit., p. 229 (1259-I-26).

(20) Memorial Histórico Español. II. Documentos de D. Affonso al Sabio. Madrid, 1851; p. 181, Doc. LXXXIV.

(21) Serrano, L.: Op. cit. Apéndice Documental, XXIII.

(22) El rey en la carta de nombramiento como Almirante lo denomina unuestro Mayordomow.

(23) GoNZŔLEZ, J: Op. cit. I, pp. 154-155.

(24) Ballesteros, A: Op. cit., P. 347. 
la familia real, el infante don Fernando, hijo primogénito de Alfonso $\mathrm{X}$ y Violante de Aragón, quien, según Ballesteros, en el otoño de 1259 ya era Mayordomo a título honorifico, pues contaba pocos años de edad (25).

A tenor de la documentación consultada ostentó el cargo de Mayordomo real desde 1261 hasta 1274 (26). Destaca, sin embargo, el dato de que en un privilegio fechado en 1272 figura Gil García como «Mayordomo del rey por el Infante don Ferrandon, figurando dos días después como Mayordomo del rey confirmando otro privilegio (27). Por esta razón pensamos que el infante don Fernando tuviese el cargo de manera nominal y quien verdaderamente ejerciera las obligaciones inherentes al puesto fuera Gil García de Azagra.

Durante su infancia estuvo a cargo de su educación Jofré de Loaisa y su esposa, quien a su vez había sido aya de la reina doña Violante. Instrucción que se vio enriquecida por su padre quien lo introduciría en cuestiones políticas y de gobierno, especialmente tras la infortunada campaña de 1272 en la que, aconsejado por los nobles y de manera especial por el maestre de Santiago, don Pelay Pérez Correa, intentó atajar el empuje musulmán y fue cercado por una celada enemiga (28).

Cuando en 1275 el monarca castellano parte al «fecho del Imperio», el infante asume las funciones gubernamentales en Castilla, y siguiendo

(25) Vid. Ballesteros, A. Op. cif., p. 118 y 236. Nació a primeros de Noviembre de 1255.

(26) Memorial Hissórico Español, I. Docs. LXXXIV, XCl, XCVIIl, CLX. Torres Fontes, J:CODOM, III. Doc. LXI. SAINz RipA, E.: Colección Diplomática de las colegiatas de Albelda y Logroño. Logroño, 1981. Docs. 24 y 63.

(27) Tokres FonTEs, J: CODOM, III. Docs. CXXVI (1272-VI-23, Alcaraz, en el que figura como lugarteniente de Mayordomo) y CXXVIl (1272-VI-25, Alcaraz, donde ya es citado como Mayordomo real). Se trata de don Gil Garéa de Azagra, el que fuera partidor mayor en el Repartimiento de Mlurcia. Vid. Torres Fontes, J: Repartimiento de Murcia. Madrid, 1960. Ya en 25 de Noviembre de 1272 aparece nuevamente como Mayordomo y privado real confirmando el acuerdo de Munilla, por el que se concertaba el matrimonio de Teobaldo, hijo de Enrique de Navarra, y Violante, hija del castellano. Del mismo modo participaria en las afablas de Burgosn, replicando a los nobles que exponían sus quejas al monarca.

(28) Ballesteros, A: Op. ait, p. 657. 
las directrices de su padre convoca las vistas de Peñafiel. Pero es ahora cuando los Benimerines irrumpen en el obispado de Sevilla e invaden el reino, por lo que don Fernando decide ir contra ellos al frente de un poderoso ejército, mas habiendo enfermado en Ciudad Real murió al poco tiempo, y sus fuerzas sólo le permitieron pedir a don Juan Núñez de Lara que defendiese los derechos al trono de su hijo don Alfonso.

Desconocemos que aconteció en la mayordomía real tras la muerte de don Fernando hasta el ejercicio de la misma por el infante don Manuel, que comienza a figurar como Mayordomo en 1278 hasta 1283, año en que es sustituido por Alfonso Fernández, sobrino del rey (29). Pero no hay que olvidar que don Manuel cesa en su puesto de Alférez el mismo año en que muere su sobrino, por lo que muy bien pudiera haber ocurrido que ya en ese mismo momento le sucediera en la mayordomía (30).

\section{LOS ALFERECES REALES EN EL SIGLO XIII}

Oficio de carácter público dentro de la corte era el de Alférez del rey, cuya función es eminentemente militar. "wca a el pertenesce de guiar las huestes, quando el rey non va ay por su cuerpo o quando non pudiese yr, e enbiase su poder. E el mismo deue tener la seña cada que el rey ouiere batalla campal_„, y también debe velar por la integridad del reino y por el cumplimiento de la justicia: «...E bien assi como pertenesce a su oficio de amparar e de acrecentar el reyno. Otrosi, si alguno fiziere perder eredamientos al rey, villa o castillo sobre que deuiese venir riepto, el lo deue fazer e ser abogado para demandarlo. E esto mismo deue fazer en los otros eredamientos o cosas que pertenescan al señorio del rey, si alguno quisiese menguar o encobrir el derecho que el rey ouiesse en

(29) Memorial Histórico Español, II. Docs. CXXXII, Cl.XIV, CCXII. Toraes Fontes, J: CO. DOM, III. Doc. Cl.l.

(30) No estudiamos aqui al infante don Manuel como Mayordomo real por cuanto al haber ocupado la alferecía mayor por un tiempo más prolongado, nos parece más adecuado tratarlo dentro de los Alféreces reales. 
ellos, manguer fuessen a tales que no ouiessen riepto. Et assi como pertenesce a su ofiçio de fazer justicia en los omes honrrados... Otrosi, a el pertenesce de pedir merced al rey por los que son sin culpa. E el deue dar por su mandado quien razone los pleytos que ouieren dueñas biudas e huerfanos fijosdalgo, quando no ouiere quien razone por ellos, ni quien tenga su razon... E por todos estos fechos tan grandes que el alferez ha de fazer conuiene en todas guisas que sea ome de noble linaje, por que aya verguença de fazer cosa que le este mal... E leal deue ser para amar la pro del rey e del reyno. E de buen seso ha menester que sea, pues que por el se han de librar los pleytos grandes que ouiere o acaescen en las huestes. Muy esforçado deue ser e sabidor de guerra.., (31). No nos detendremos más en este aspecto, pues la definición del cargo y su cometido que nos brinda Alfonso $\mathrm{X}$ es de por si clarificadora.

\section{LOPE DIAZ DE HARO (1217-1236)}

Patriarca de una de las familias nobiliarias que mayor influencia tendrían en la vida política castellana del Siglo XIII. Constituyó uno de los principales puntales que favorecieron la subida al trono de Fernando III, y tras la pacificación del reino a la muerte de don Alvaro Núnez de Lara, consolidaría su ascendencia en las altas esferas de la corte, si bien es cierto que en la proclamación de Valladolid anduvo en posturas contradictorias, debido a la lealtad que profesaba a la reina doña Berenguela, a su parentela con la casa de Lara y a su matrimonio con la hija natural de Alfonso IX, monarca con el que se enfrentará tras la muerte del pequeño infante don Enrique.

Pese a todas estas vicisitudes ocupó la alfereća real sin ninguna interrupción, ni siquiera cuando se encontraba apartado de la corte, desde los primeros días del reinado de Fernando III hasta su muerte acaecida

(31) Partidas, II, IX, XVI. 
en 1236 (32); sus buenos y leales servicios fueron recompensados espléndidamente por el monarca de quien obtuvo la villa de Pedroso de río Tobía con todos sus términos (33). El afianzamiento de su poder, paralelo al declive de las casas de Lara y Cameros, le permitió gozar de las tenencias de Cameros, Rioja con Nájera, Haro, Alava, Vizcaya y Bureba, posesión ésta que le ocasionó no pocos problemas al enfrentarse con el obispo de Calahorra, apoyado por la clerecía de la diócesis burgalesa, lo que le valió ser amenazado de excomunión.

Su poder alcanzó tal extremo que llegó a ocupar las tenencias de 17 castillos pertenecientes al monarca sin que previamente hubiera habido entrega alguna del soberano; y este hecho tal vez pudiera ser la causa de la tensión que por un tiempo enturbió las relaciones entre Fernando III y su Alférez, especialmente después de la conquista de Ubeda y posterior regreso de don Fernando a Burgos, que derivó en un enfrentamiento de Díaz de Haro con las huestes reales. Crisis que quedó solventada por la paz de Palenzuela, en Febrero de 1235, por la que don Lope se sometia a la autoridad de Fernando III.

\section{DIEGO LOPEZ DE HARO (1237-1241 y 1243-1254)}

Don Lope Diaz de Haro fallece el 15 de Enero de 1237, pero la vacante oficial del cargo se anuncia en fecha anterior, exactamente el 8 de

(32) Vid. Gonzít.ez, J.: Op. cit. II. Docs. 2, 4, 6-11, 13-18, 20, 22, 28-30, 32, 34-36, 39-47, $50-53,57,58,63-65,67,68,70,72,74,75,78,80-82,84,85,87-90,93,95,98-100,102,103$, $108-111,113,115-119,121,132-134,136,138-140,142-148,150,153-158,160,161$, $163-166,168-170,172,173,175,177-179,181,184-188,193-195,197-199,201,203-211$, $213,216-218,222,223,225,229,231,238,240-244,247,249-251,254-257,260,265-269$, $272,275,278,280,281,284,287,289,292,295-298,306,308,311-313,316,318,321,322$, $325,336,338-343,345,352,354,358-360,367,370,372,373,383,385,386,392-394,396$, $398,399,401-403,408,409,411,413-415,418,419-426,431,432.436,439,441,443,444$, $447,449-451,454,455,457,459,461,462,466,469-473,476,479,481,483,484,487,491$ y 494. También Burriel., A. M.: Op. ait., pp. 411, 422, 425 y 428. Y Castro Toledo, J: Colección Diplomática de Tordesillas. Valladolid, 1981. Doc. 33.

(33) En 1218-XIJ-25, al poco tiempo de haber accedido al cargo. Ballestreros, A.: Op. cif., pp. 21, 22, 31 y 37. GonzÁlez, J.: Op. cit. J; p. 130. 
Diciembre de 1236 (34) y se prolongará por espacio de dos meses, hasta el 4 de Febrero del año siguiente (35).

El puesto de Alférez del rey sería ocupado por don Diego López de Haro, señor de Vizcaya e hijo del anterior, desde 1237 a 1241 en una primera etapa (36), perdiéndolo a ralz de su enfrentamiento con el rey, motivo por el que es sustituido por el infante don Alfonso (37), volviendo a recuperarlo en una segunda etapa desde 1243 a 1254 (38).

Como sobrino del rey e íntimamente ligado a las altas esferas de la política castellana, aparece pronto protagonizando importantes episodios de la vida de Castilla desde los primeros años del mandato de Fernando III, como lo ponen de manifiesto la dirección de la mesnada castellana hacia Córdoba en 1236, acompañado por su hermano Alfonso López, y la ocupación de las tenencias de Castilla la Vicja y Bureba en fechas aún más tempranas. Ya desde joven sería reconocido como señor de Vizcaya, título al que se fueron sumando otros muchos como el de canónigo de Burgos, que ostentaba en 1252.

El cese temporal en su puesto vino provocado por sus enfrentamientos con el rey castellano que, según don Diego, le hacía objeto de múltiples agravios. A la rebeldía del señor de Vizcaya no tardó en responder Fernando IIl, despojándolo de todas las tenencias y cargos que ocupaba, motivando con ello las correrias y asaltos que cometiera López de Haro

(34) Si bien en un documento fechado en Burgos el 15 de Enero de 1237 se expresa amortuo Lupo Didaci de Faro, Alferiz Dominis Regis Confs, es decir después de muerto Lope Dlaz confirma este privilegio. Burrate., A. M.: Op. cit.; p. 430.

(35) GonzÁlezz, J: Op. cit. l; p. 119.

(36) Consta en los privilegios rodados desde el 2-IX-1237 hasta el 12-VII-1241. Burrier, A. M.: Op. cit., pp. 439, 440, 447 y 450. Torres Fontes, J: CODOM, III. Doc. I. Gonzilez J: Op. ais. l, p. 133.

(37) El infante don Alfonso ocuparía la alferecía real clesde el I de Agosto de 1242 hasti el 22 de Septiembre del mismo año. Pese a que no hay anuncio oficial de la vacante, ésta se constata en los privilegios desde el 2 de Febrero al 20 de .Marzo de 1242.

(38) Burriel, A. M.: Op. cit., pp. 470, 493, 508, 515, 527, 536. Torres Fontes, J.: CODOM, III, Docs. VII, IX, XV, XVII. 
en tierras de Vizcaya a donde acudió el ejército real para combatirlo, pero ante la superioridad e las huestes del monarca, don Diego no tuvo más salida que aceptar las condiciones impuestas por Fernando III. Sin embargo, poco duraría la tranquilidad, puesto que al no serle devueltas sus tenencias ni proveido otra vez de la alferecía real, volvió a sublevarse de nuevo y marchó a Vizcaya, en donde acosado por el rey se somete por segunda vez; ahora le son reintegradas las tenencias incrementadas con la de Alcaraz y, finalmente, es nombrado Alférez en Febrero de 1243, cargo que ocupará hasta su muerte en los primeros años del reinado de Alfonso X.

Entre los eficaces y valiosos servicios que a lo largo de su vida prestó a la monarquia castellana, destaca su participación en la conquista de Murcia, acompañando al entoces infante don Alfonso (39) y, posteriormente, en Andalucía. Tras la conquista de la capital hispalense desarrolló una importante labor ocupándose de los problemas del reino castellano, siendo recompensado con el otorgamiento de un donadío en Sevilla.

A la muerte de don Diego López de Haro se inicia un largo espacio de tiempo, tres años, en el que la alferecía mayor del rey está vacante (40), hasta que figura al frente del cargo el infante don Manuel.

INFANTE DON MANUEL (1259-1274)

Hijo menor de Fernando III, nacido en Carrión en 1234, pronto comenzará a ejercer su influencia y así en 1255, cuando el cargo de Alférez está vacante, le es encomendado el mando de la hueste real destinada a Soria para poner freno a las pretensiones de navarros y aragoneses sobre las tierras vascas. En 1259, con el cambio de entidades en la esfe-

(39) El 28 de Septiembre de 1244 testificaba un documento de Abu Zeit, en la capital del Segura. GonzÁlezz, J: Op. cit., p. 135.

(40) Desde 1255 a 1259. Vid. Torres Fontes, J: CODOM, III. Docs. XXI, XXVI, XXIX, XI.VI. También CAstro Toledo, J.: Op. cit., Doc. 40. 
ra política castellana, asciende al puesto de Alférez real que desempeñará sin interrupción hasta 1274, según nos consta en los privilegios (41), año en el que, por razón de su embajada a Roma por la cuestión imperial, debió cesar en el cargo, pues en 1278 aparece desempeñando la alferecía el infnate don Juan (42), mientras que don Manuel confirma los privilegios como Mayordomo real, nuevo cargo que ostentará hasta 1282 (43), en que es sustituido por Alfonso Fernández (44).

El 25 de Abril de 1262 su hermano lo nombraba Adelantado Mayor del reino de Murcia (45) y como tal acudió al llamamiento de don Alfonso para terminar con la rebelión mudéjar del año 1264, incorporándose al ejército que Jaime I había organizado en Orihuela para emprender la toma de la capital murciana. Rebelión musulmana que también va a afectar a extensos dominios de don Manuel, ya que los islámicos de Villena, Elda y Elche se sublevan contra su señor exponiendo sus reivindicaciones al rey de Aragón, que actuará como mediador en la contienda prometiendo a los sublevados la permanencia en sus heredades y la vigencia de sus propias leyes y costumbres, a cambio de volver a la obediencia del infante; pero a pesar de esta mediación de don Jaime, tras la entrevista de Alcaraz entre los reyes de Castilla y Aragón, el infante toma posesión de Elche pero no de Villena (46).

En 1273 se inician una seric de problemas que se agudizan dos años más tarde cuando muere el infante don Fernando y surge la cuestión sucesoria al trono castellano. Don Manuel tomará partido por don Sancho

(41) Memorial Hissórico Español, I. Docs. LXXXIV, XCI, XCVIII, CIX, CXXXII. Baltesteros, A. Op. cit., p. 229. Torres Fontes, J.: CODOM, III. Docs. JIl, I.XI, LXVI, I.XXIX, XCV, CVI, CXXVI. Sainz Ripa, E.: Op. cit., Doc. 6.3.

(42) Ballesteros, A.: Op. cit, p. 85.

(43) Memorial Histórico Español, II. Docs. ClXIV, CCXII. Toraes liontes, J.: CODOM, IJI. Doc. CL.I.

(44) Ballestizos, A.: Op. cit., pp. 1014-1015.

(45) Ballesteros, A.: Op. ait., p. 346.

(46) Jomax, D. W: E/ Infante don Manuel. En aDon Juan Manuclı, VII Centenario. Murcia, 1982; p. 171. 
frente a la facción nobiliaria encabezada por el señor de Lara, que defendía los derechos sucesorios del hijo de don Fernando de la Cerda, don Alfonso. En esta fase crítica que sucede a las Cortes de Sevilla de 1278, convocadas para jurar al infante don Sancho como heredero de Castilla, don Manuel manejará los hilos de la política peninsular e incluso el propio heredero pedirá su asesoramiento para consolidar su puesto. Es ahora cuando el infante don Manuel abandona definitivamente a aquel que tanto bien le habia proporcionado, y en las Cortes de Valladolid de 1282 sentencia que el gobierno del reino, rentas, fortalezas, etc. pasaran a su sobrino el infante Sancho, a pesar de que el rey aún vivía (47).

Este fue el espaldarazo final de aquel que con su astucia ejercía su poder en la sombra; su influencia no admite discusión aún cuando sus consejos no reflejan los intereses del reino, por lo que su lealtad hacia Alfonso $\mathrm{X}$ en muchos casos era más que dudosa. Al lado del monarca castellano permaneció mientras fue poderoso, pero en las horas de desgracia don Manuel abandona a su hermano y sigue las huellas de los desleales, aliándose al nuevo impulso que representaba don Sancho, pero la muerte no le permitió ver el éxito de su sobrino, pues falleció en Penafiel en el mes de Diciembre de 1283, antes de que muriese su hermano el rey y Sancho IV le sucediese.

(47) Ballesteros, A.: Op. cil., pp. 625-633 y 957-966. 